\title{
Injustiça na escola: representações sociais de alunos do ensino fundamental e médio*
}

\author{
Renata Aparecida Carbone \\ Maria Suzana De Stéfano Menin \\ Universidade do Estado de São Paulo — Presidente Prudente
}

\section{Resumo}

Neste artigo apresenta-se o relato sobre duas pesquisas que buscaram investigar como os alunos do ensino fundamental e médio de escolas públicas e particulares do município de Presidente Prudente representam situações de injustiça na escola, bem como seus agentes e os tipos de ações que cometem. Dois conjuntos de dados foram analisados: 1) respostas obtidas por meio de questões abertas incluídas num questionário aplicado em 480 alunos em 1999, em alunos da $8^{a}$ série do ensino fundamental e $1^{\text {a }}$ série do ensino médio, nas quais foram selecionadas, para análise, as respostas que tivessem a escola como local de injustiça; 2) respostas de alunos da $5^{\text {a }}$. série do ensino fundamental em questões sobre injustiça na escola aplicadas em 2003. Para análise teórica, foram utilizadas as abordagens da Psicologia do Desenvolvimento Moral de Piaget e Kohlberg e da Representação Social, criada por Moscovici. Comparando as duas pesquisas, a de 1999 e a de 2003, conclui-se que em nenhuma das séries a escola aparece como uma "comunidade justa" e que prevalecem os casos de injustiça retributiva e legal. Como principais agentes de injustiças aparecem, primeiramente, o professor perante seus alunos e, em segundo lugar, os alunos entre eles mesmos. Os alunos de escola particular apontaram mais o professor como agente de injustiças que os de escola pública. Entre esses as injustiças entre alunos foi mais citada. Os alunos de escola pública se posicionaram contra regras escolares que se opõem às necessidades pessoais com mais veemência que os de escola particular.

\section{Palavras-chave}

Correspondência:

Psicologia Social - Justiça - Escola.

Renata Aparecida Carbone

Rua João Braz Mathias, n. 175

19014-190 - Presid. Prudente -SP

e-mail:

carbone@prudente.unesp.br

"Esta pesquisa foi desenvolvida com

o apoio financeiro da Fapesp. 


\title{
Injustice at school: social representations of elementary and secondary school students*
}

\author{
Renata Aparecida Carbone \\ Maria Suzana De Stéfano Menin \\ Universidade de São Paulo — Presidente Prudente
}

\begin{abstract}
This article reports on two studies that aimed at the investigation of how students from elementary and secondary schools, both private and public, from the town of Presidente Prudente (SP) represent situations of injustice at school, as well as their agents and the kind of actions they take. Two sets of data were analyzed: 1) open answers to a questionnaire submitted in 1999 to 480 pupils from the $8^{\text {th }}$ grade of the elementary school and the $1^{\text {st }}$ grade of secondary school; the answers selected were those in which reference was made to injustice at school; 2) answers given in 2003 by students of the $5^{\text {th }}$ grade of the elementary school to questions about injustice at school. The theoretical analysis was based on the approach of the Psychology of Moral Development of Piaget and Kohlberg, and on the Social Representation approach created by Moscovici. Comparing the 1999 and the 2003 studies the conclusions can be drawn that none of the school series see the school as a "just community", and that retributive and legal injustices prevail. The main agents of injustice are revealed to be teachers (against students), followed by students (against other students). Students from private schools point the teachers as the agents of injustice more often that students from public schools. The latter put first the injustices among students; they also opposed more strongly the rules that go against personal needs than their counterparts from private schools.
\end{abstract}

\section{Keywords}

Social psychology - Justice - School.

Contact:

Renata Aparecida Carbone

Rua João Braz Mathias, n. 175

19014-190 - Presid. Prudente - SP

e-mail:

carbone@prudente.unesp.br

* The research has been sponsored

by Fapesp. 


\section{Discussões sobre justiça e injustiça}

Foram feitas duas pesquisas com o objetivo de investigar de que forma os alunos do ensino fundamental e médio de escolas públicas e particulares do município de Presidente Prudente representam situações de injustiça na escola bem como seus agentes e os tipos de ações que cometem. É possivel investigar as percepções de injustiças na medida em que elas se revelem por meio de representações de acontecimentos, de casos reais ou de queixas que podem ser suscitadas por diferentes instrumentos, sejam eles diferentes meios de comunicação (televisiva, falada, escrita, imagens, etc.), conversas informais com colegas, debates públicos, entre tantos outros. Nessas representações, podem aparecer diferentes concepções do que se considera injusto que se ancoram em diferentes conceituações de justiça. No entanto, esse pode se mostrar um campo complexo de pesquisa, uma vez que as definições de justiça podem ser inúmeras, assim como as formas de estudá-la na psicologia.

Perelman (1999) enfatiza que a decisão sobre que formas de justiça priorizar depende de muitas outras variáveis que vão de uma escala de valores adotada, que pode mudar historicamente, até os jogos de poder entre os envolvidos nessas escolhas.

Na Psicologia do Desenvolvimento, Piaget (1932/1977) foi pioneiro em investigar como crianças desenvolvem concepções de justiça e injustiça. Em seus estudos foram encontrados três grandes períodos de evolução dessas concepções:

\footnotetext{
Justiça Heterônoma

De sete a oito anos, aproximadamente, a justiça subordina-se à autoridade adulta; justo, portanto, é o que está de acordo com as ordens impostas pela autoridade dos adultos e assim toda sanção é tida como legítima, necessária e constituindo mesmo o princípio da moralidade; o que prevalece é o respeito unilateral sobre o
}

respeito mútuo. Há ainda a forte presença da imanência na conceituação do que é justo: há a crença, por parte das crianças, na justiça automática que emana da natureza física e dos objetos inanimados.

\section{Igualitarismo Progressivo}

De oito a onze anos, aproximadamente, há o igualitarismo progressivo; há o desenvolvimento progressivo da autonomia e primazia da igualdade sobre a autoridade e as únicas sanções consideradas realmente como sendo legítimas são as que decorrem da reciprocidade. Há o progressivo decréscimo da crença na justiça imanente e o ato moral é procurado por si só, independente da sanção.

\section{Justiça Autônoma}

Acima dos doze anos a justiça igualitária é temperada por preocupações de equidade; isto é, a criança não concebe mais os direitos iguais senão relativamente à situação particular de cada indivíduo.

Esses "períodos" não chegam a ser estágios, para Piaget, mas "fases que caracterizam desenvolvimentos limitados” (1977, p .273).

Em relação à questão: "0 que é algo injusto?" Piaget obteve quatro tipos de respostas:

1. Injusto como sinônimo de condutas contrárias às ordens recebidas do adulto: mentir, roubar, quebrar algo, em criança menores de sete anos, em média.

2. Injusto como o contrário do que é estabelecido nas regras do jogo, por exemplo, trapacear. 3. Injusto como as condutas contrárias à igualdade, seja a desigualdade nas sanções ou nos tratamentos. Essas duas respostas podem ser encontradas em crianças acima de oito anos, em média.

4. Injusto se referiu às injustiças relativas à sociedade adulta, de ordem social, econômicas, políticas; uma resposta mais típica em adolescentes.

Podem-se encontrar, de acordo com 
Piaget, quatro tipos de justiça e injustiça daí derivados nas respostas das crianças ou adolescentes:

1. Injustiça legal: cometer atos considerados errados de acordo com a lei, como por exemplo: matar, roubar, etc.

2. Injustiça retributiva: injustiça como atribuição de castigo de forma arbitrária e desproporcional ao ato; como por exemplo: punir um inocente ou não castigar um culpado. 3. Injustiça distributiva: injustiça como forma de tratamento desigual de acordo com a pertinência social, econômica, política, religiosa, cultural, etc; como por exemplo: tratamento desigual entre pessoas ricas e pobres.

4. Injustiça social: injustiça como um atentado à dinâmica coletiva por meios políticos, culturais, morais, sociais, econômicos, como por exemplo: a fome, a miséria, a guerra.

Outro estudioso sobre questões de justiça e injustiça, também na Psicologia do Desenvolvimento, foi Kohlberg (1992). Ele descobriu, a partir de respostas de crianças, adolescentes e adultos a dilemas hipotéticos, três niveis de julgamento moral: pré-convencional, convencional e pós-convencional. Esses níveis se subdividem em estágios que revelam diferentes critérios sobre o que é considerado justo ou certo moralmente falando.

Os estágios de julgamento moral são, para Kohlberg,

formas de raciocínio empregadas em certas situações e não a simples presença de diferentes conteúdos morais por preferência a certos valores (...); o julgamento moral é paralelo aos desenvolvimentos sociais e intelectuais que nele, também, interferem. (Kohlberg, 1992, p. 31)

Para se entender os diferentes estágios é preciso compreender as relações que são estabelecidas entre o eu - as normas - e as expectativas sociais. Assim, no nível pré-convencional (menos de nove anos de idade) as normas e as expectativas sociais são externas ao indivíduo, portanto, pouco consideradas; no estágio convencional (adolescentes/adultos), há a conformidade com a manutenção das normas sociais: identificação do eu com estas, com as expectativas sociais e com as autoridades que as personificam; e, no nível pós-convencional (minoria de adultos), as normas passam a ser aceitas ou não em função de princípios norteadores.

Nesses três níveis as "operações da justiça" tais como: a igualdade, a reciprocidade, a equidade, a universalidade, e as formas da justiça dis-tributiva, retributiva e comutativa, se aplicam a aspectos diferentes do meio social e em extensões também diversas.

Kohlberg (1992) destaca, ainda, que os estágios apresentam uma seqüência invariante e hierárquica, isto é, cada estágio é mais adiantado e melhor do que o outro em termos de qualidade e de raciocínio neles empregados.

\section{Pesquisas sobre justiça injustiça}

Os desenvolvimentos teóricos de Piaget e Kohlberg sobre justiça marcaram as pesquisas que se seguiram sobre esse tema, tanto teórica como metodologicamente. Hutz e Dell'Aglio (1995) apresentaram uma revisão das pesquisas que vêm sendo realizadas no Brasil sobre justiça distributiva. Nelas, investigou-se como as regras da justiça distributiva são utilizadas de acordo com os princípios de igualdade, equidade, ou ainda, necessidade, em histórias que contrapuseram a distribuição de um bem (notas, salário, lucros, etc.) entre protagonistas que se diferenciaram quanto ao mérito (esforço, habilidades), quanto à produção ou quanto às necessidades.

Segundo Menin (2000b), as pesquisas sobre justiça têm resultados limitados a situações de laboratório que são criadas para as investigações e que, na maior parte das vezes, não conseguem reproduzir as complexidades das situações de vida, como por exemplo, as que se referem às muitas características nas 
quais as pessoas são diferentes na vida real; o que traz muita dificuldade na escolha dos critérios de justiça. Sabe-se que a utilização de uma regra de justiça em relação a outras pode variar em função da situação, dos fatores relativos às pessoas, e dos fatores socioculturais, tais como os que envolvem as ideologias, os valores, as normas e regras sociais, a religião e outros. Menin (2000b) considera, além dessas observações, que a metodologia usada nessas pesquisas, histórias artificiais de distribuição de bens em função do mérito, das obras, das necessidades ou, mesmo de forma injusta, limitam o levantamento dos critérios espontâneos que poderiam ser identificados em diferentes populações. Os sujeitos das pesquisas que têm utilizado histórias apenas escolhem entre os critérios de justiça já dados pelos pesquisadores.

No campo da Psicologia Social, Assmar $(1998,2000)$ retomando vários trabalhos sobre justiça e injustiça destaca que neles se tem priorizado a Teoria da Equidade, segundo a qual a equidade seria o único princípio utilizado pelas pessoas para apontar uma situação de repartição de bens como justa ou injusta. Segundo a autora, esses estudos têm acontecido, também, prioritariamente em laboratório, em situações programadas artificialmente em que os participantes das pesquisas encontram situações já estruturadas, as quais devem julgar como justas ou injustas. Nas palavras de Assmar: "Negligenciaram-se, assim, os processos sociopsicológicos básicos da interação, envolvidos na troca eqüitativa, em favor de uma ênfase unilateral nos processos intrapsíquicos dos participantes individuais, socialmente isolados" (Assmar, 1998, p. 122). Em sua pesquisa, concluiu que a interação social deve ter um efeito diferenciado no modo como os grupos se comportam diante de situações injustas.

\section{Estudos de justiça e representações sociais}

Menin (2000b) acredita que os trabalhos sobre representações sociais são os que de fato consideram concepções espontâneas de justiça ou injustiça. São exemplos disso os trabalhos de Jakubowska (1991) e deste com Branicka (1994) e algumas das investigações de Doise (1994a, 1995) e colaboradores (Doise 1991, Doise, Spini, Jesuíno e Emler, 1994a; Doise e Herrera, 1994b; e Doise, Clemence, Rosa e Gonzáles, 1995).

Jakubowska (1991), por meio de uma história descrita a seus entrevistados, questionou sobre que leis mais justas um povo livre deveria adotar para si; e, a partir das respostas, descreveu as diversas concepções de justiça que poderiam ser usadas por diferentes grupos. Como principais resultados, a autora verificou tendências tais como:

\begin{abstract}
- os mais jovens conceberam a justiça como traços de caráter e de condutas específicas que eles consideraram "boas" ou definiram a justiça legal; - entre os adolescentes de quatorze a quinze anos, a justiça foi entendida como estabelecendo condições de proteção do bem social. Foram encontradas três tendências: a) justiça como comportamento conforme as leis; b) justiça como exigência de punição justa aos malfeitores; c) justiça como exigência de uma avaliação objetiva;

- para os mais velhos, entre dezessete e dezoito anos, também foram encontradas três tendências: a) justiça como uma conduta em acordo com a consciência individual; b) como apreciação objetiva e um julgamento justo; c) justiça como igualdade diante da lei, aplicação igual da lei para todos.
\end{abstract}

Em outra pesquisa, Jakubowska e Branicka (1994) investigaram o conceito de justiça em crianças e jovens por meio de questões abertas, e as categorias que mais apareceram foram as de justiça como condutas desinteressadas, justiça como condutas dirigidas pela própria consciência e justiça como conformidade legal; mas essas concepções variaram na freqüência de suas indicações e nos tipos de justiças mais concebidas conforme a época das pesquisas (1989 e 1991) e ainda conforme a idade dos entrevistados. 
Os estudos de Doise e colaboradores (1994a, 1994b, 1995) evidenciaram que o que as pessoas consideram como direitos humanos, justos ou necessários, ou o que consideram como injustiça, ou seja, o atentado aos direitos humanos, pode se modificar em função de: histórias culturais diferentes; de profissões nas quais as pessoas têm diferentes necessidades e contatos com necessidades de outros; classes sociais e níveis educacionais que podem permitir, ou não, uma visão mais ampla ou restrita dos direitos humanos; adesões políticas e religiosas específicas, graus de fatalismo e sensibilidade a diferentes conflitos sociais e outros.

Em conclusão, esses últimos estudos apontam, direta ou indiretamente, que as representações de justiça e de injustiça podem ser mais do que estágios de julgamento, mas construções possíveis de certas classes sociais ou grupos, em razão das pertinências sociais, de histórias socioculturais comuns, de práticas sociais cotidianas.

Na pesquisa realizada por Menin (2000a), perguntou-se a jovens acusados de cometer infrações o que consideravam como injustiça e obteve respostas muito diversas, que lembravam as categorias obtidas por Jakubowska e que variaram de acordo com a classe social dos entrevistados. Jovens de classes sociais mais desfavorecidas indicavam injustiças que haviam presenciado em seus bairros ou na vizinhança, ao passo que outros jovens de classes sociais mais altas indicavam exemplos tirados da televisão.

Menin (2000b) investigou novamente quais as representações que cerca de 480 adolescentes, em média com dezesseis anos, tinham de injustiça. Apareceu como resultado uma grande diversidade de respostas e as variáveis que mais as afetaram foram às relacionadas à classe social dos alunos. Quanto pior o bairro de residência dos alunos, o nível ocupacional dos pais e a rigidez dos alunos em suas respostas a outras questões sobre leis, maior a severidade dos julgamentos, a dificuldade em representar, conceituar e exemplificar injustiças. As duas idéias de injustiça que mais apareceram foram às relacionadas à justiça legal e as relacionadas à justiça retributiva. Notou-se, também, que a idéia de um julgamento injusto dos alunos aproximou-se da idéia de ausência de defesa jurídica apontada nos estudos de Doise em vários países, como algo que seria um grave atentado aos direitos humanos $(1991,1995)$.

Nessa pesquisa de Menin (2000b) não foram analisados, nos exemplos de injustiça, aqueles apontados como ocorrendo na escola, embora tenham sido freqüentes. Recentemente ${ }^{1}$ foram questionados jovens de primeira série do ensino médio sobre situações de injustiça na escola e cerca da metade dos jovens descreveu situações escolares consideradas como injustas. Entre os exemplos dados, sobressairam aqueles em que os jovens se consideraram como acusados injustamente por professores ou inspetores em atos cometidos ou, ainda, queixaramse por terem recebido um castigo (suspensão, ser mandado para fora da classe, chamadas da direção, etc.) desproporcional ao ato cometido. Tais respostas podem sinalizar que a escola pode ser um lugar percebido como injusto em várias de suas funções e relações sociais.

Esses apontamentos levantam mais uma possibilidade de investigação nos estudos sobre injustiça. Assim sendo, a escola, enquanto um espaço diverso, culturalmente múltiplo, que abrange elementos sociais e organizacionais de questões sociais multifacetadas, traz a incumbência dos questionamentos acerca da representação de alunos e professores sobre as formas de administração, gestão e direcionamento escolar. É imprescindível, então, captar as representações que esses agentes têm do universo escolar e suas dimensões.

Nesse sentido, a percepção complexa de justiça na escola poderá ser percebida e estudada a partir da sua reconstrução por meio de representações sociais.

As concepções de justiça/injustiça podem

1. Relatório de pesquisa do Grupo de Pesquisa Valores, Educação e Formação de Professores: "Ética na escola: valores de alunos" (2002). 
ser entendidas como representações sociais. De acordo com Jodelet:

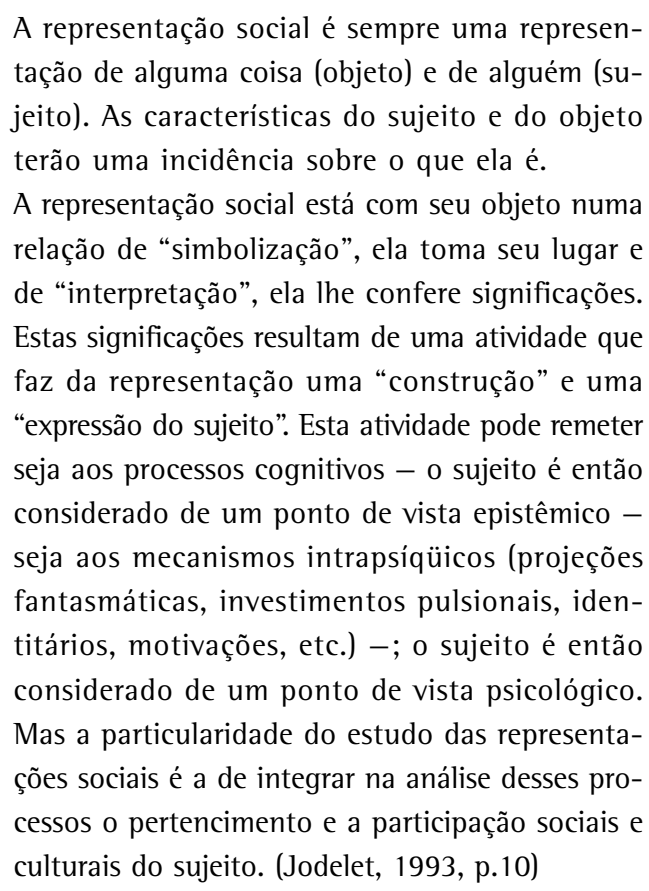

0 termo representações sociais foi introduzido por Moscovici (1978) a partir de seu trabalho sobre como se dava o processo de socialização de conceitos psicanalíticos e sua "transformação" para servir para outros propósitos e funções pelas pessoas no cotidiano.

De acordo com Sá (1998), as bases referenciais das representações sociais estão pautadas na vertente de Émile Durkheim que procurava explicar os fenômenos religiosos, científicos, temporais, a partir de conhecimentos inerentes à sociedade. Durkheim entendia que os fatos sociais eram produto de uma ampla gama de conhecimentos oriundos das mais diversas fontes e formas no tempo e no espaço, que se combinavam e se misturavam acumulando-se durante as gerações e transferindo-se para as posteriores. A essa multiplicidade de comportamentos e saberes ele atribuiu o nome de "representações coletivas”. No entanto, Moscovici considera que as representações coletivas de Durkheim apresentam pontos falhos que não permitem a explicação dos novos fenômenos, os quais apontavam para a necessidade de uma concepção "flexível" sobre os indivíduos, sobre o que pensam, o que identificam, o que sentem, o que falam.

Numa sociedade, o novo se apresenta constantemente mediante o universo científico ou por meio das novas tecnologias ou mesmo da dúvida e do questionamento que as relações interpessoais provocam, e que precisam ser decifradas, descobertas, reinventadas. Esta é a matéria-prima das representações sociais: aquilo que causa estranhamento e pede uma resposta, uma inteligibilidade, uma familiaridade. Tornar familiar aquilo que é estranho no universo cotidiano é a principal tarefa da "teoria do senso comum", por seu poder convencional e prescritivo sobre a realidade.

De acordo com Doise e colaboradores (1994, 1995), as representações sociais assumem o papel de tomada de decisões que organizam e regulam os sistemas cognitivos e as dinâmicas individuais e sociais, nos quais as modalidades de expressão atualizam os contextos e as relações de forma organizacional.

As representações sociais como "teorias do senso comum" têm particularidades e fazem emergir uma identidade de grupo a partir das experiências vividas nele. 0 próprio grupo passa a se caracterizar por essas representações partilhadas por seus membros em razão do grau de adesão ou não aos tipos de opiniões, e são ancoradas coletivamente apesar das heterogeneidades individuais. Os fatores culturais e as diferentes formas de viver influenciam muito na escolha dos elementos que aparecem como estruturadores da representação. A variedade e a diversidade contextual são fortes elementos na conceituação dos olhares em representação social.

Sabendo que a escola é um espaço onde se tecem relações com diferentes expectativas que variam de acordo com as funções sociais e escolares e os papéis que cada um ocupa na dinâmica escolar, a teoria das representações sociais vem contribuir para se perceber e esclarecer criteriosamente esses saberes coletivos 
que são partilhados por um grupo e que nem sempre estão explícitos ou claros. No que se refere às concepções de injustiça na escola, estas podem ser representações sociais na medida em que podem vir de diferentes práticas, por serem coletivas, por serem comuns a um determinado grupo e por estruturarem elementos centrais de representação. Tais representações podem ser de um determinado grupo quando as práticas, vivências, classe social, são elementos partilhados por esse grupo. A organização dessas "teorias da realidade" pode se relacionar com outras visões que o aluno tem a respeito de sua escola, da finalidade da escola, de suas perspectivas e expectativas futuras. A descoberta destes elementos é de essencial relevância na elaboração de um currículo ou programa de ensino que priorize a formação de um aluno crítico e autônomo.

\section{Objetivos da pesquisa}

0 objetivo desta pesquisa foi identificar as representações sociais de alunos sobre injustiças que têm como espaço a escola. Tal objetivo foi investigado por meio de dois conjuntos de dados: as respostas a duas questões sobre injustiça numa população de 480 adolescentes de $8^{\text {a }}$ série do ensino fundamental e $1^{\text {a }}$ série do ensino médio de escolas públicas e particulares de Presidente Prudente, cujas representações sobre injustiça foram levantadas em questionário aplicado em 1999 e as respostas a várias questões sobre injustiça obtidas em $2003 \mathrm{em}$ duas classes de $5^{\text {a }}$ série do ensino fundamental, uma de escola particular e outra de escola pública.

\section{Metodologia}

Num primeiro momento, foi realizada a análise dos 480 questionários que foram aplicados em três escolas particulares e oito escolas públicas de Presidente Prudente em 1999 e que tiveram como objetivo, entre outros, identificar as representações de injustiça dos ado- lescentes. Duas questões foram investigadas: "Você já viu acontecer alguma injustiça? Conte um caso" e "Nesse mundo que você vive, conhecendo tudo o que você conhece e já viu, o que você denunciaria como injusto?”. Foram separadas para análise apenas as respostas desses alunos que evidenciaram injustiças ocorridas na escola (72 respostas).

Os alunos dessas escolas se encontravam na faixa etária dos treze aos quinze anos de idade e das 72 respostas selecionadas, 84\% foram de alunos de escolas públicas.

A partir da seleção das 72 respostas que apontaram injustiças na escola, foi realizada, então, uma categorização das mesmas exibindo-se quem era o agente de injustiça, quais suas vítimas e que tipo de ação foi realizada. Estas categorias serão apresentadas na Tabela 1 , nos resultados.

Num segundo momento (2003) foi investigado, a partir de um novo questionário aplicado em duas salas de $5^{\text {a }}$ série do ensino fundamental, como a escola aparece nessas representações de injustiça; que tipo de injustiça é mais citado quando os jovens se referem às suas vivências escolares, e em que espaços da escola mais aparecem às percepções de injustiça. 0 questionário conteve, também, uma escala com casos de injustiça que se inspirou no questionário anterior (1999) e em situaçõesdilema sociocognitivas. Essas situações pretendiam verificar se os alunos consideram como justo ou injusto a ocorrência de infração de regras ou normas disciplinares em função de questões sociais, de saúde de parente e de trabalho, bem como a intervenção externa para resolução de conflitos no ambiente escolar.

Para esse segundo questionário, foram escolhidas salas de uma escola particular e de uma escola pública da cidade de Presidente Prudente; a primeira com 39 alunos e a segunda com 34. Os alunos da escola particular tinham entre dez (36\%) e onze (64\%) anos de idade; os alunos da escola pública entre dez (49\%), onze (42\%) e doze (9\%) anos. Os meninos eram maioria na escola particular (54\%). As me- 
ninas somavam $46 \%$. Na escola pública os meninos eram 49\% da sala e as meninas representavam a maioria (51\%). Quanto à situação econômica dos pais das crianças: na escola particular os pais ocupavam cargos em profissões que apresentavam remuneração superior a dez salários mínimos em média, cargos estes de proprietários, gerência e de profissionais liberais (médicos, dentistas, advogados); na escola pública ocorreu o oposto: os pais ocupavam, em sua maioria, cargos de profissionais manuais especializados (técnico, eletricista, marceneiro, etc.), que apresentavam renda inferior a dez salários mínimos. Situação semelhante também ocorre com as mães dos alunos de ambas as escolas.

\section{Resultados do primeiro conjunto de dados}

No primeiro questionário analisado, das 72 respostas que se referiam à injustiça na escola, obtidas inicialmente a partir dos 480 questionários que foram aplicados por Menin em 1999, onze foram de escolas particulares e 61 de escolas públicas, tanto de $8^{\text {a }}$ série como de $1^{\circ}$ colegial. Essas respostas aparecem na Tabela 1 "Tipos de injustiças na escola e seus agentes”, em que foram categorizadas juntando-se dados de escolas particulares e públicas.

Na Tabela 1 são apresentadas sete categorias de respostas com diferentes agentes de injustiça e suas correspondentes vítimas: os professores (23\%), agentes indeterminados (21\%), os alunos entre si (18\%), o governo (15\%), a direção da escola $(12,5 \%)$, a polícia $(5,5 \%)$ e os alunos com relação aos professores $(4,2 \%)$

Analisando cada categoria vemos na Tabela 1, em primeiro lugar, com o maior número de ocorrência, a categoria cujos agentes de injustiças contra alunos são os professores. Dentro dessa categoria ressalta-se, primeiramente com 12,6\%, as afirmações relativas ao professor: "acusar, punir, dar nota baixa a alunos por comportamento inadequado”. Outras respostas aparecem de forma mais pontual, como o favoritismo do professor por alguns alunos e erro na atribuição de faltas. Os exemplos mais freqüentes de injustiças cometidas pelos professores parecem evidenciar erros dos professores nas correções ou em castigos que dão aos alunos e o uso de notas de maneira punitiva e não correlacionada, somente, a aprendizagem escolar.

Um segundo tipo de categoria de respostas aparece apontando como principal agente de injustiças na escola os alunos e, como vítimas desses, os próprios alunos. A resposta que aparece mais freqüentemente é: "alunos acusarem injustamente outros por comportamento inadequado" (9,8\%). As injustiças cometidas entre os próprios alunos podem sinalizar a existência de conflitos em sala de aula que se apóiam em práticas agressivas, quer moral, verbal ou fisicamente, que não permitem a observância de um acordo pedagógico estabelecido entre os próprios alunos. Além disso, como já observado em pesquisa anterior (Menin, 1985), a delação em escolas parece ser uma prática freqüente e, de certa forma, incentivada por professores, o que acaba por resultar em situações freqüentes de injustiça.

Outro tipo de categoria traz como agente de injustiça no ambiente escolar o governo; nesse caso as principais vítimas são os professores e os alunos. As respostas mais freqüentes são: “ensino de má qualidade" $(8,4 \%)$ e "salário de professores” (4,2\%). Essas concepções de injustiça podem evidenciar certas representações já bastante comuns sobre a escola pública, que estão difundidas no Brasil. As idéias sobre o descaso do governo com a qualidade das escolas, a condição do trabalho dos professores e seus salários fazem parte da nossa cultura, seja entre alunos de escolas públicas ou de escolas particulares, quando se fala em "injustiças nesse país".

Outra categoria aponta a direção ou coordenação da escola como principais agentes de injustiças e as vítimas, os alunos. Nessa categoria, as repostas foram muito diversificadas, apresentando casos pontuais de injustiça, embora 
Tabela 1- Tipos de injustiça na escola e seus agentes

\begin{tabular}{|c|c|c|}
\hline Do professor aos alunos & $\begin{array}{l}\text { Número de } \\
\text { respostas }\end{array}$ & Porcentagem \\
\hline Favoritismo da professora por alguns alunos & 2 & 2,8 \\
\hline Ser mau professor & 1 & 1,4 \\
\hline Impunidade de comportamento năo adequado & 1 & 1,4 \\
\hline Erro na atribuição de faltas & 2 & 2,8 \\
\hline Acusar, punir, dar nota baixa a alunos por comportamento inadequado & 9 & 12,6 \\
\hline Professor: faltar um mẻs e ao retomar da prova & 1 & 1,4 \\
\hline Ter que fazer prova & 1 & 1,4 \\
\hline SUBTOTAL & 17 & $23,6 \%$ \\
\hline Entre alunos & $\begin{array}{l}\text { Número de } \\
\text { respostas }\end{array}$ & Porcentagem \\
\hline Alunos acusarem injustamente outros por comportamento inadequado & 7 & 9,8 \\
\hline Violência e morte na escola & 2 & 2,8 \\
\hline Alunos tirarem vantagem ou prejudicarem outros em trabalhos de grupo & 2 & 2,8 \\
\hline Acabar com materiais escolares & 2 & 2,8 \\
\hline SUBTOTAL & 13 & $18 \%$ \\
\hline Do governo aos professores e aos alunos & $\begin{array}{l}\text { Número de } \\
\text { respostas }\end{array}$ & Porcentagem \\
\hline Ensino de má qualidade & 6 & 8,4 \\
\hline Falta de computadores nas escolas & 1 & 1,4 \\
\hline Violação do direito de acesso da criança à escola & 1 & 1,4 \\
\hline Salário dos professores & 3 & 4.2 \\
\hline SUBTOTAL & 11 & $15,3 \%$ \\
\hline Da direção-coordenação aos alunos & $\begin{array}{l}\text { Número de } \\
\text { respostas }\end{array}$ & Porcentagem \\
\hline Acusar ou punir de forma arbitrária um aluno por comportamento inadequado & 2 & 2,8 \\
\hline Favoritismo da coordenaçăo por alguns alunos & 1 & 1,4 \\
\hline Punir toda a classe por causa do comportamento de alguns alunos & 2 & 2,8 \\
\hline Erro da escola no processo de avaliaçăo & 1 & 1,4 \\
\hline Quebra de confiança na relação direção-aluno & 1 & 1,4 \\
\hline Direção nấo toma providência em relação à violência na escola & 1 & 1,4 \\
\hline Coordenaçăo dar razăo para comportamento agressivo da professora contra aluna & 1 & 1,4 \\
\hline SUBTOTAL & 9 & $12,5 \%$ \\
\hline Da policia aos alunos & $\begin{array}{l}\text { Número de } \\
\text { respostas }\end{array}$ & Porcentagem \\
\hline Policia na escola agindo com racismo & 1 & 1,4 \\
\hline Chamar a policia para aluno que está aprontando na escola & 3 & 4,2 \\
\hline SUBTOTAL & 4 & $5,5 \%$ \\
\hline Do aluno ao professor & $\begin{array}{l}\text { Número de } \\
\text { respostas }\end{array}$ & Porcentagem \\
\hline Alunos desrespeitarem ou brigarem com professor & 3 & 4,2 \\
\hline Agentes indeterminados & $\begin{array}{l}\text { Número de } \\
\text { respostas }\end{array}$ & Porcentagem \\
\hline Acusar ou punir injustamente um aluno por comportamento inadequado & 5 & 7 \\
\hline Impunidade de comportamento năo adequado & 1 & 1,4 \\
\hline Fico ter escola melhor porque pode pagar & 1 & 1,4 \\
\hline Cigarro ou drogas nas escolas & 5 & 7 \\
\hline Outros & 3 & 4,2 \\
\hline SUBTOTAL & 15 & $21 \%$ \\
\hline TOTAL & 72 & $100 \%$ \\
\hline
\end{tabular}


quase todos se refiram à forma de injustiça retributiva ligada à atribuição de pena a um infrator. Essa categoria remete à reflexão de que injustiças acontecem em todos os espaços do ambiente escolar e que não é exclusividade de uma relação entre professores e alunos ou que ocorre apenas na sala de aula, mas que atinge outras esferas do cotidiano escolar.

Em outra categoria a polícia é apontada como agente de injustiças na escola e a resposta que mais aparece refere-se a "chamar a polícia para aluno que está aprontando na escola" $(4,2 \%)$. Esses exemplos parecem apontar que, aos olhos de alguns alunos, quando a escola assume a necessidade de um agente externo a sua dinâmica para a resolução de conflitos que são de ordem escolar e não judicial, atesta a sua fragilidade na gestão e organização de seus espaços e organismos enquanto instituição.

Por fim, a categoria que aponta o aluno como agente de injustiça contra o professor na escola traz como resposta "alunos desrespeitarem ou brigarem com o professor" $(4,2 \%)$. Esta categoria parece demonstrar que os alunos reconhecem que ao desrespeitar o professor estão rompendo com um código disciplinar que precisa ser respeitado. Questiona-se, porém, se esse respeito está pautado na obediência por medo da punição à infração ou se, por outro lado, ancora-se no respeito consensual.

Aconteceram exemplos de injustiça que não continham um agente bem delimitado. As duas categorias que mais aparecem nesses casos foram: "acusar ou punir injustamente um aluno por comportamento inadequado" (7\%) e "cigarro e drogas nas escolas" (7\%).

Por mais que variassem os agentes de injustiça nesses exemplos, dos professores aos alunos, coordenação, governo, polícia, notamos a predominância de duas formas de justiça e de injustiça delas derivadas: a retributiva e a legal. Ou seja, as idéias de injustiça mais associadas à escola são as de infração e a de penalidade. Ou a escola é injusta porque nela não se cumprem códigos disciplinares, e, nesse caso, os alunos são os agentes de injustiça, ou é injusta porque nelas se penalizam os alunos erroneamente, e, nesse caso, os professores são os agentes.

Assim, parece que a escola e seus agentes se apresentaram como uma comunidade justa (Kohlberg, Power e Higgins, 1997) na qual as relações escolares são marcadas pelo exercício da democracia e ancoradas em práticas dialógicas e não coercitivas ou injustas.

Tabela 2: 0 que você acha da escola em que estuda?

\begin{tabular}{|c|c|c|c|c|}
\hline \multirow[b]{2}{*}{ Categorias } & \multicolumn{2}{|c|}{ Escola Particular } & \multicolumn{2}{|c|}{ Escola Pública } \\
\hline & $\begin{array}{l}\text { Número de } \\
\text { respostas }\end{array}$ & Porcentagem & $\begin{array}{l}\text { Número de } \\
\text { respostas }\end{array}$ & Porcentagem \\
\hline $\begin{array}{l}\text { Apreciaçāo positiva com ênfase nos } \\
\text { relacionamentos interpessoais e de lazer }\end{array}$ & 7 & $17 \%$ & 15 & $43 \%$ \\
\hline $\begin{array}{l}\text { Apreciaçāo positiva com ênfase no processo } \\
\text { ensino-aprendizagem }\end{array}$ & 18 & $44 \%$ & 5 & $14 \%$ \\
\hline $\begin{array}{l}\text { Apreciaçāo positiva com ênfase na formaçāo } \\
\text { pessoal }\end{array}$ & 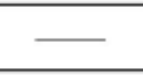 & & 4 & $11 \%$ \\
\hline Apreciaçăo positiva sem justificativa & 11 & $27 \%$ & 8 & $23 \%$ \\
\hline $\begin{array}{l}\text { Apreciaçåo positiva com ressalva no a specto } \\
\text { recreativo/pedagógico }\end{array}$ & 3 & $8 \%$ & 1 & $3 \%$ \\
\hline Apreciaçăo negativa em relaçăo aos docentes & 1 & $2 \%$ & $\underline{ }$ & $\underline{ }$ \\
\hline $\begin{array}{l}\text { Apreciaçăo negativa e } \mathrm{m} \text { relaçăo ao a specto } \\
\text { fisico escolar }\end{array}$ & - & - & 1 & $3 \%$ \\
\hline Nẫo respondeu/sem sentido & 1 & $2 \%$ & 1 & $3 \%$ \\
\hline TOTAL & 41 & $100 \%$ & 35 & $100 \%$ \\
\hline
\end{tabular}


Nessa escola haveria a circulação dos diferentes papéis escolares que faria com que os envolvidos no processo ensino-aprendizagem se sentissem responsáveis pelo bem-estar do grupo, respeitando, deste modo, as regras consensualmente.

Como tivemos poucas respostas de alunos de escolas particulares sobre injustiça na escola, porque a amostra foi pequena, não foi possível investigar nessa primeira análise se a escola aparece como mais injusta para alunos de escolas públicas ou particulares e se há um tipo de injustiça que predomina na queixa dos alunos conforme a escola a que pertencem; 0 que se procurou no segundo estudo.

\section{Resultados do segundo conjunto de dados}

A seguir, será apresentada a categorização dos dados obtidos por intermédio do segundo questionário, aplicado em duas salas de $5^{\text {a }}$ série do ensino fundamental, sendo uma particular, com 39 alunos; e outra pública, com 34 alunos.

A primeira questão pedia que os alunos descrevessem sua opinião a respeito da escola em que estudavam. As categorias obtidas podem ser vistas na Tabela 2 .

$\mathrm{Na}$ Tabela 2 a categoria "Apreciação positiva com ênfase nos relacionamentos interpessoais e de lazer" aparece mais freqüentemente na es- cola pública (43\%), onde os alunos ressaltam que a escola é um espaço no qual se pode estabelecer muitas amizades e usufruir momentos de lazer e diversão; por exemplo: "Legal. Boa. Nela eu encontrei amigos e nós aprendemos várias matérias" (aluna de dez anos, escola pública). Na escola particular, essa categoria aparece com menor freqüência (17\%). Uma segunda categoria, "Apreciação positiva com ênfase no processo de ensino-aprendizagem”, apresenta maior número de respostas na escola particular (44\%), onde os alunos ressaltam a importante necessidade do ensino de boa qualidade e de se ter bons professores; por exemplo: "A melhor escola de Presidente Prudente. Gosto muito mesmo. 0 sistema é muito bom, os professores ensinam claramente todas as matérias" (aluna, dez anos, escola particular). Na escola pública, essa categoria aparece com um número de respostas menor (14\%). A categoria “Apreciação positiva sem justificativa” aparece numa freqüência parecida nas duas escolas; $27 \%$ na escola particular e $23 \%$ na escola pública. Considerando todas as categorias, verificamos que não houve diferença significativa entre as escolas. No entanto, se só considerarmos a apreciação positiva sobre a escola vemos que alunos de escola pública parecem privilegiar relacionamentos pessoais e os de escola particular parecem privilegiar a aprendizagem escolar. Isto

Tabela 3: Para você, o que é uma injustiça?

\begin{tabular}{|c|c|c|c|c|c|}
\hline \multirow[b]{2}{*}{ Categorias } & \multirow[b]{2}{*}{ Tipo } & \multicolumn{2}{|c|}{ Escola particular } & \multicolumn{2}{|c|}{$\begin{array}{l}\text { Escola Pública } \\
\end{array}$} \\
\hline & & $\begin{array}{l}\text { Número de } \\
\text { respostas }\end{array}$ & Porcentagem & $\begin{array}{l}\text { Número de } \\
\text { respostas }\end{array}$ & Porcentagem \\
\hline $\begin{array}{l}\text { Roubar, matar, violentar, mentir, } \\
\text { fazer coisa errada }\end{array}$ & Legal & 14 & $35 \%$ & 10 & $29 \%$ \\
\hline $\begin{array}{l}\text { Não poder fazer o que quer/o que } \\
\text { gosta }\end{array}$ & Pessoal & 3 & $7,5 \%$ & 6 & $17 \%$ \\
\hline $\begin{array}{l}\text { Coisa não igual para todos/ } \\
\text { favoritismo na aplicaçăo das le is }\end{array}$ & Distributiva & 6 & $15 \%$ & 3 & $9 \%$ \\
\hline $\begin{array}{l}\text { Guerra, pobreza, falta de emprego, } \\
\text { poluiçāo ambiental,desigualdade } \\
\text { social }\end{array}$ & Social & 5 & $12,5 \%$ & 5 & $14 \%$ \\
\hline Racismo & Distributiva & 3 & $7,5 \%$ & - & - \\
\hline $\begin{array}{l}\text { Acusar, culpar, punir inocente } \\
\text { injustamente }\end{array}$ & Retributiva & 8 & $20 \%$ & 4 & $11 \%$ \\
\hline Nẫo sei, nấo respondeu, outros & - & 1 & $2,5 \%$ & 7 & $20 \%$ \\
\hline TOTAL & - & 40 & $100 \%$ & 35 & $100 \%$ \\
\hline
\end{tabular}


pode relacionar-se, por exemplo, com as finalidades e com os métodos de ensino empregados nas escolas, visto que as escolas particulares, historicamente, objetivam o ingresso de seus alunos nas universidades e posteriormente no mercado de trabalho, por isso o desempenho de seus alunos deve estar associado, constantemente, com a otimização do processo ensino-aprendizagem. Já as escolas públicas, embora legalmente, tenham os mesmos objetivos, não são esses que mais transparecem ou marcam as representações de seus alunos.

A Tabela 3 expõe os resultados da questão sobre a definição de injustiça ("Para você, o que é uma injustiça”). Nela podem ser observadas semelhanças e diferenças interessantes entre alunos de escolas públicas e particulares. Entre todos, a categoria mais presente de injustiça é a "legal”, relacionada a atos de infração. Tal resultado reproduz os obtidos na pesquisa anterior de Menin (2000b e 2002), em que 480 adolescentes definiram injustiça. Assim, seja entre mais jovens ou mais velhos, parece que a idéia de injustiça associada à ilegalidade é a mais freqüente entre os estudantes.

$\mathrm{Na}$ escola particular aqui pesquisada surgem, na Tabela 3, outras formas de injustiça: a retri-butiva ligada a castigos $(20 \%)$, a distributiva ligada a desigualdades de tratamento $(15 \%)$ e a social, ligada a problemas da sociedade $(12,5 \%)$. Já nas escolas públicas surge, em segundo lugar, os casos de "Não sei" ou de não-resposta relacionados a não fazer o que gosta $(17 \%)$ e a casos sociais (14\%). Esses resultados reproduzem os anteriores de Menin (2000b, 2002), em que foram bem mais freqüentes, entre alunos de escola pública, as dificuldades em definir e identificar injustiças.

A Tabela 4 expõe os resultados da terceira questão: "Você já viu acontecer alguma injustiça na sua escola? Sim ou não? Explique”.

A categoria que mais aparece na Tabela 4 e bem mais recorrente na escola pública é a que diz que os alunos nunca viram ou presenciaram nenhuma injustiça na escola em que estudam: $68 \%$ na escola pública e $46,5 \%$ na escola particular. A categoria: "Violência/ desrespeito entre os próprios alunos" aparece numa freqüência semelhante nas duas escolas: $16 \%$ na escola particular e $13 \%$ na escola pública; assim como a categoria: "Rigidez na aplicação das normas escolares” que aparece com 10\% das respostas na escola particular e $13 \%$ na escola pública. Uma categoria que ocorre somente na escola particular é "Tratamento desigual entre salas" com 20\% das respostas. Há diferença significativa entre as escolas. ${ }^{2}$ É interessante verificar que, em ambas as escolas, os alunos dizem, em sua maioria, que nunca viram ou presenciaram injustiças na escola; no entanto, essa resposta é mais freqüente na escola pública. Talvez esses alunos tenham

2. $\left(\chi^{2}=6,722, g l=2, p=0,035\right)$.

Tabela 4: Vocể já viu acontecer alguma injustiça na sua escola?

\begin{tabular}{|l|c|c|c|c|}
\cline { 2 - 5 } \multicolumn{1}{c|}{} & \multicolumn{2}{c|}{ Escola Particular } & \multicolumn{2}{c|}{ Escola Pública } \\
\hline & $\begin{array}{c}\text { Número de } \\
\text { respostas }\end{array}$ & Porcentagem & Número de respostas & Porcentagem \\
\hline Nāo & 19 & $46,5 \%$ & 26 & $68 \%$ \\
\hline $\begin{array}{l}\text { Violência/ desrespeito entre os } \\
\text { próprios alunos }\end{array}$ & 7 & $16 \%$ & 5 & $13 \%$ \\
\hline $\begin{array}{l}\text { Rigidez na aplicação das normas } \\
\text { escolares }\end{array}$ & 4 & $10 \%$ & 3 & $13 \%$ \\
\hline $\begin{array}{l}\text { Pessoas ou alunos acusarem outro } \\
\text { aluno inocente }\end{array}$ & 3 & $7,5 \%$ & 1 & $3 \%$ \\
\hline Tratamento desigual entre salas & 8 & $20 \%$ & - & - \\
\hline Pessoas colando & - & - & 1 & $3 \%$ \\
\hline TOTAL & $\mathbf{4 1}$ & $\mathbf{1 0 0}$ & $\mathbf{3 6}$ & \\
\hline
\end{tabular}




\begin{tabular}{|c|c|c|c|c|}
\hline & \multicolumn{2}{|c|}{ Escola Particular } & \multicolumn{2}{|c|}{ Escola Pública } \\
\hline & $\begin{array}{l}\text { Número de } \\
\text { respostas }\end{array}$ & Porcentagem & $\begin{array}{l}\text { Número de } \\
\text { respostas }\end{array}$ & Porcentagem \\
\hline Não & 26 & $67 \%$ & 30 & $85 \%$ \\
\hline Alunos desrespeitarem professor & - & - & 1 & $3 \%$ \\
\hline Violência entre alunos/chantagens & 1 & $2 \%$ & 2 & $6 \%$ \\
\hline Alunos prejudicarem a aprendizagem de outros alunos & 1 & $2 \%$ & 2 & $6 \%$ \\
\hline Rigidez na aplicação das normas escolares & 4 & $12 \%$ & - & - \\
\hline $\begin{array}{l}\text { Professora "marcar" alunos que corversam/ favoritismo de } \\
\text { professora }\end{array}$ & 3 & $8 \%$ & - & - \\
\hline Professor mandar aluno para fora & 2 & $5 \%$ & - & - \\
\hline Professor nāo "marcar" alunos que conversam & 1 & $2 \%$ & - & - \\
\hline Erro do professor na atribuição de notas & 1 & $2 \%$ & - & - \\
\hline TOTAL & 39 & $100 \%$ & 35 & $100 \%$ \\
\hline
\end{tabular}

Tabela 6: Freqüência de situações conflituosas na escola

\begin{tabular}{|c|c|c|c|c|}
\hline \multirow[b]{2}{*}{ Tipos de situações } & \multicolumn{2}{|c|}{ Escola Particular } & \multicolumn{2}{|c|}{ Escola Pública } \\
\hline & $\begin{array}{l}\text { Nunca acontece } \\
\text { e/ou aconteceu } \\
\text { uma vez }\end{array}$ & $\begin{array}{l}\text { Aconteceu várias } \\
\text { vezes e/ou } \\
\text { acontece sempre }\end{array}$ & $\begin{array}{l}\text { Nunca acontece } \\
\text { e/ou aconteceu } \\
\text { uma vez }\end{array}$ & $\begin{array}{l}\text { Aconteceu várias } \\
\text { vezes e/ou } \\
\text { acontece sempre }\end{array}$ \\
\hline $\begin{array}{l}\text { 01) Professor ter preferéncia por alguns alunos } \\
\text { e tratá-los melhor do que os outros }\end{array}$ & (22) $56 \%$ & (17) $44 \%$ & (29) $88 \%$ & (04) $12 \%$ \\
\hline $\begin{array}{l}\text { 02) Alunos tirarem vantagens ou prejudicarem } \\
\text { outros alunos em trabalhos de grupo }\end{array}$ & (24) $61 \%$ & (15) $39 \%$ & (22) $67 \%$ & (11) $33 \%$ \\
\hline 03) Violência na escola & (16) $41 \%$ & (23) $59 \%$ & (19) $54 \%$ & (16) $46 \%$ \\
\hline $\begin{array}{l}\text { 04) Direção dar razão para professor mesmo } \\
\text { quando este professor está errado }\end{array}$ & (23) $59 \%$ & (16) $41 \%$ & (28) $82 \%$ & (06) $18 \%$ \\
\hline 05) Alunos desrespeitarem um professor & (18) $46 \%$ & (21) $54 \%$ & (16) $46 \%$ & (19) $54 \%$ \\
\hline $\begin{array}{l}\text { 06) Escola chamar a policia para resolver } \\
\text { problemas de alunos mal comportados }\end{array}$ & (38) $100 \%$ & 一 & (34) $100 \%$ & - \\
\hline 07) Alunos fumarem na escola & (28) $71 \%$ & (11) $29 \%$ & (30) $85 \%$ & (05) $15 \%$ \\
\hline $\begin{array}{l}\text { 08) Alunos usarem drogas na escola (maconha } \\
\text { e outras) }\end{array}$ & (38) $97 \%$ & (01) $3 \%$ & (33) $94 \%$ & (02) $6 \%$ \\
\hline 09) Reclamaçăo de pais & (12) $31 \%$ & (27) $69 \%$ & (22) $64 \%$ & (12) $36 \%$ \\
\hline 10) Aluno tirar lanche de outro menor & (36) $92 \%$ & (03) $8 \%$ & (26) $74 \%$ & (9) $26 \%$ \\
\hline $\begin{array}{l}\text { 11) Aluno acusar outro de algo que ele nåo fez, } \\
\text { colocando a culpa no inocente }\end{array}$ & (20) $51 \%$ & (19) $49 \%$ & (20) $57 \%$ & (15) $43 \%$ \\
\hline $\begin{array}{l}\text { 12) Professor acusar um aluno de algo que ele } \\
\text { năo fez e puni-lo }\end{array}$ & (29) $74 \%$ & (10) $26 \%$ & $(30) 88 \%$ & (04) $12 \%$ \\
\hline $\begin{array}{l}\text { 13) Professor punir toda sala por causa do mau } \\
\text { comportamento de alguns alunos }\end{array}$ & (25) $65 \%$ & (14) $35 \%$ & (31) $91 \%$ & (03) $9 \%$ \\
\hline
\end{tabular}

dificuldades em conceituar ou utilizar critérios claros de seleção de situações conflituosas entre professores e alunos ou entre os próprios alunos, porque essas situações não são postas em discussão. Podem ser vividas mas não são problematizadas, de modo que não se constroem sobre elas representações sociais.

Outra questão trata de injustiças presenciadas especificamente na sala de aula: "Na sala de aula você já presenciou alguma injustiça? Sim ou não?. O que aconteceu de injusto?”.

A categoria que mais apareceu, como podemos ver na Tabela 5, foi: "Não", com 85\% das repostas na escola pública e $67 \%$ na escola particular.

A segunda categoria mais freqüente na Tabela 5 foi "Rigidez na aplicação das normas escolares”, que apareceu somente na escola 
particular com $12 \%$ das respostas. As demais categorias aparecem em menor freqüência em ambas escolas. É curioso notar que na escola pública as três outras categorias, de baixa freqüência, onde aparecem respostas, se referem a injustiças cometidas por alunos. Quando juntamos as categorias referentes às injustiças cometidas somente pelo professor, notamos que foram os alunos de escola particular que mais afirmaram a sua ocorrência. Novamente os alunos têm dificuldades em representar situações injustas. Porém, percebe-se uma nítida diferença no que se prioriza ou se considera como injusto nas duas escolas. Na escola particular, os alunos apontaram mais fortemente injustiças referentes à rigidez na aplicação das normas escolares, visto que na escola particular foram priorizados aspectos pedagógicos e normativos. Na escola pública foram priorizadas as relações interpessoais e as categorias de injustiças mais freqüentes estavam relacionadas com injustiças cometidas pelos alunos. ${ }^{3}$

Uma outra questão, cujas respostas estão na Tabela 6 , pedia que os alunos marcassem, entre as treze situações propostas, quais eles consideravam que apareciam com maior ou menor freqüência na escola dentro de quatro possíveis graduações: "Nunca aconteceu”, "Aconteceu uma vez", "Aconteceu várias vezes" e "Acontece sempre”. Na Tabela 6, essas quatro graduações foram agrupadas em dois grupos de duas, de acordo com as freqüências: "Nunca aconteceu" e "Aconteceu uma vez" numa graduação, e "Aconteceu várias vezes" e "Acontece sempre” noutra graduação. Essas graduações foram agrupadas para que os dados pudessem ser mais bem comparados e verificarmos as possiveis diferenças entre as duas escolas de maneira mais clara.

Na Tabela 6 vê-se em cada linha um tipo de injustiça (treze no total), oferecido como alternativa para que os alunos marcassem a graduação de sua ocorrência. 0 teste $\chi^{2}$ foi aplicado para cada uma das treze linhas da Tabela 6. As linhas 1, 4, 9, 10 e 13 apresentaram resultados que apontam diferença significativa entre as escolas. ${ }^{4} \mathrm{Na}$ linha 1 verificamos que os alunos da escola particular apontaram, mais veementemente que os da escola pública, o professor como cometendo injustiça com os alunos, quando trataos de forma desigual. Na linha 4, os alunos da escola particular apontaram, com maior freqüência que os da escola pública, a direção como cometendo injustiças contra os alunos por dar razão ao professor mesmo quando ele está errado. Na linha 9, a situação "Reclamação de pais" aconteceu mais freqüentemente, segundo os alunos, na escola particular do que na escola pública. $\mathrm{Na}$ linha 10, a situação "Tirar lanche de aluno me-

3. (Diferença significativa $\chi^{2}=12.391, g l=2, p=0,002$ ).

4. Para a Linha $1=\left(\chi^{2}=8,568, g l=1, p=0,003\right)$; para a Linha $4=\left(\chi^{2}\right.$ $=4.715, g l=1, p=0.030)$; para a Linha $9=\left(\chi^{2}=8,407, g l=1, p=0,004\right)$, para a Linha $10\left(\chi^{2}=4,410, g l=1, p=0,004\right)$, para a Linha $13\left(\chi^{2}=\right.$ $7,453, g l=1, p=0,006)$.

\begin{tabular}{|c|c|c|c|c|c|c|c|c|}
\hline & & & & & \multirow{2}{*}{\multicolumn{4}{|c|}{ Exola Püblica }} \\
\hline \multirow{3}{*}{ Tabela 7: 0s dilemas } & \multicolumn{4}{|c|}{ Exola Particular } & & & & \\
\hline & \multicolumn{2}{|c|}{ Justo } & \multicolumn{2}{|c|}{ Injusto } & \multicolumn{2}{|c|}{ Jisto } & \multicolumn{2}{|l|}{ Injusto } \\
\hline & $\begin{array}{l}\text { Nimere de } \\
\text { respostas }\end{array}$ & $\mathrm{s}$ & $\begin{array}{l}\text { Mümero de } \\
\text { respostas }\end{array}$ & $\%$ & $\begin{array}{l}\text { Nümero de } \\
\text { respostas }\end{array}$ & $\%$ & $\begin{array}{l}\text { Nümero de } \\
\text { respostas }\end{array}$ & $\%$ \\
\hline $\begin{array}{l}\text { Situaçấo 1: "0 a aluno que colou na prowa } \\
\text { porque teve que cuider da mảe doente" }\end{array}$ & 13 & $30 \%$ & 30 & $70 \%$ & 14 & $44 \%$ & 19 & $56 \%$ \\
\hline $\begin{array}{l}\text { Sítuaçấo 2: "A protessora que ajuda o aluno } \\
\text { que precisa sair mais cedo para trabalhar" }\end{array}$ & 8 & $18 \%$ & 35 & $82 \%$ & 19 & $54 \%$ & 17 & $46 \%$ \\
\hline 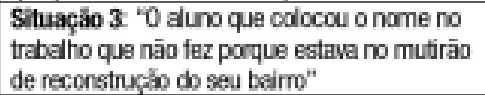 & 7 & $16 \%$ & 35 & $84 \%$ & 14 & $40 \%$ & 21 & $60 \%$ \\
\hline $\begin{array}{l}\text { Sítuaçāo 4: "O caso da professora que chama } \\
\text { a policia para controlar alunas que estão } \\
\text { aprortando na escola" }\end{array}$ & 10 & $22 \%$ & 33 & $77 \%$ & 12 & $33 \%$ & 24 & $67 \%$ \\
\hline $\begin{array}{l}\text { Situaçăo 5. "O aluno bagunceino que será } \\
\text { expu'so da escola m bagunçar pela tercera } \\
\text { vez" }\end{array}$ & 33 & $84 \%$ & 6 & $16 \%$ & 15 & $43 \%$ & 20 & $57 \%$ \\
\hline
\end{tabular}


nor" foi marcada mais veementemente por alunos da escola particular do que por alunos da escola pública. Por fim, na linha 13, a situação que mostra o professor punindo os alunos por mau comportamento foi marcada mais freqüentemente por alunos também de escola particular.

As linhas 3, 5, e 11, não apresentaram diferenças significativas entre as escolas porque a porcentagem foi semelhante em ambas as escolas. Isto é, os alunos marcaram, em proporções parecidas, as categorias "Nunca acontece" e "Aconteceu várias vezes".

Nas linhas 2, 6, 7, 8 e 12 também não se verificaram diferenças significativas entre as escolas que marcaram mais fortemente, dentre as situações propostas, a categoria "Nunca acontece".

Na Tabela 7 estão expostas as situaçõesdilema sociocognitivas apresentadas aos alunos. Tais dilemas evidenciaram, nos três primeiros casos, um conflito entre a necessidade pessoal do aluno e a quebra de uma regra ou a ocorrência de uma infração a uma norma imposta pela escola, e nas duas últimas situações o uso da punição em casos de condutas em desacordo com as normas escolares.

Essa Tabela 7 foi construída apresentando, nas linhas, as situações-dilema propostas e, nas colunas, a porcentagem de respostas que consideram cada situação como justa ou injusta e que somam 100\% em cada linha para cada escola.

Pelo que se pode perceber, nos três primeiros casos está em questão uma necessidade individual do aluno em relação a uma norma escolar e sua possibilidade ou não de infração. No primeiro caso verificamos que, na escola particular, os alunos estão mais intensamente convencidos que os de escola pública de que a norma deve ser obedecida (70\%), e que, portanto, cabe ao aluno buscar formas alternativas de resolver o problema sem ter que cometer uma infração. Na escola pública, os alunos também acreditam que as normas devem ser obedecidas, mas esse número aparece com uma freqüência menor em relação à escola particular (56\%); no entanto, estatisticamente, esta diferença não foi significativa. ${ }^{5} \mathrm{Na}$ segun- da situação, novamente, os alunos da escola particular, em sua grande maioria (82\%), consideram injusto privilegiar uma necessidade pessoal em razão da desobediência de uma norma preestabelecida. Ao contrário, dos alunos da escola pública, 54\% deles consideram justo que uma necessidade pessoal se sobressaia ao cumprimento de regras escolares. Houve, neste caso, diferença significativa entre as escolas. ${ }^{6}$

No terceiro dilema, os alunos da escola particular afirmam, mais veementemente que os da escola pública, ser injusto que as regras da escola não sejam observadas em virtude de questões pessoais (84\% das respostas dos alunos de escola particular e $60 \%$ das respostas de alunos de escola pública). Neste dilema encontrou-se diferença significativa entre as escolas. ${ }^{7}$

$\mathrm{Na}$ quarta situação que questiona o uso da punição como meio de restabelecer o equilíbrio pedagógico, os alunos da escola particular estão fortemente convencidos (77\%) de que é função da escola e não da polícia resolver problemas escolares. 0 mesmo ocorre com alunos de escola pública (67\%). Não se verificou diferença significativa entre as escolas. ${ }^{8}$

Na quinta e última situação, há uma oposição entre alunos de escola particular e alunos de escola pública. Os alunos de escola particular estão mais preocupados com o cumprimento de uma norma preestabelecida (84\%), a o passo que alunos de escola pública (57\%) consideram injusta uma expulsão, mesmo que o aluno já tenha sido avisado. Nesta situação houve diferença significativa entre as escolas. ${ }^{9}$ Com isso, percebe-se que alunos de escola particular foram mais convencionais (Kohlberg, 1992), pontuando como mais correta a obediência às regras e a sua incorporação; de modo que a não-observância de tais regras, mesmo por motivos pessoais, implica o cometimento de uma infração e, portanto, precisa ser reparada com
5. $\left(\chi^{2}=1,212, g l=1, p=0,271\right)$.
6. $\left(\chi^{2}=10,172, g l=1, p=0.001\right)$
7. $\left(\chi^{2}=5,240, g l=1, p=0,022\right)$.
8. $\left(\chi^{2}=0,990, g l=1, p=0,320\right)$
9. $\left(\chi^{2}=14,113, g l=1, p=0,000\right)$. 
uma punição. Já os alunos de escola pública (57\%) foram mais pré-convencionais (Kohlberg, 1992) e apresentam uma visão mais relativa a respeito do cumprimento dessas normas: fatores pessoais e interpessoais parecem interferir na hora de decidir se uma regra pode ou não ser violada talvez por terem, esses alunos, maior contato com situações que inspirem tais decisões. Pode-se questionar que valores motivaram os alunos da escola particular obedecerem mais as normas escolares em desfavorecimento das necessidades pessoais do que os alunos de escolas públicas que, por sua vez, estiveram mais favoráveis à infração dessas normas. Questionamos se isso se deve por uma questão de atraso nos raciocínios morais ou por identificação com problemas de certas classes sociais. De acordo com Piaget (1932/1977) e Kohlberg (1992), os alunos de escolas públicas estariam mais "atrasados" moralmente falando do que os alunos de escolas particulares, pois aqueles relativizariam as normas em função de necessidades pessoais e estes não.

Assim como nos estudos de Doise e colaboradores (1994a, 1994b, 1995) e de Menin (2000b e 2002), a representação de injustiça se modificou de acordo com as diferentes classes socioeconômicas e, provavelmente, de acordo com as vivências e práticas cotidianas que os diferentes grupos têm. Essas representações foram marcadas por elementos que são comuns a cada grupo e por ele partilhado. Fundamentando-se na teoria das representações sociais, essas representações de injustiça se ancoram em diferentes práticas sociais e permitem a construção de teorias coletivas que representam um grupo e ao mesmo tempo permitem que esse grupo organize esses saberes num movimento dialético e dialógico.

\section{Considerações Finais}

Pretendeu-se levantar nessa pesquisa as representações de injustiça em situações escolares. Para tanto, foram comparados dados obtidos em 1999 de classes de $8^{a}$ série do ensino fundamental e $1^{\text {a }}$ série do ensino médio e em 2003, classes de $5^{\text {a }}$ série do ensino fundamental. No primeiro questionário foram apresentadas aos alunos questões abertas sobre injustiça (sua descrição, casos e denúncias de situações injustas) e, depois, selecionadas as respostas que tinham como situação de injustiça à escola. Os tipos de resposta que aparecem apontam, em ambas as escolas, o professor como principal agente de injustiça contra alunos, seguindo-se os alunos entre si. Os casos de injustiça escolar centraram-se em exemplos de injustiça retributiva e legal.

No segundo questionário foram apresentadas a alunos de $5^{\text {a }}$ série do ensino fundamental tanto questões abertas, semelhantes às anteriormente utilizadas, como questões mais voltadas à identificação da freqüência de ocorrência de situações de injustiça na escola. As respostas ilustradas nas várias tabelas evidenciaram que exemplos espontâneos de injustiça na escola não são muito freqüentes e que os tipos de injustiça que mais são apontados na escola particular se referem ao professor agindo injustamente em relação aos alunos quando aplica rigidamente as normas e trata diferentemente salas, ao passo que na escola pública se afirmam mais exemplos de injustiças cometidas entre os próprios alunos, que preconizam necessidades pessoais e relações interpessoais. Verificou-se, também, que nas duas escolas os alunos apontam, em primeiro lugar, exemplos de injustiça legal e em segundo lugar, na escola particular, são mais marcantes exemplos de justiça retributiva e distributiva enquanto na escola pública aparecem as repostas do tipo "não sei" e "justiça pessoal". Quando foram oferecidos exemplos de situações injustas (Tabela 7), na escola particular os alunos defenderam a observância das normas escolares, mesmo em prejuízo de necessidades pessoais. Já na escola pública, os alunos, assumiram uma atitude mais personalista e pareceram considerar mais as necessidades pessoais daquele que está "infringindo" uma norma escolar Talvez estes alunos tenham se sentido mais próximos daqueles protagonistas das situações propostas 
e identifiquem-se com suas necessidades, levando em conta aspectos pessoais e interpessoais na avaliação das regras. Os alunos de ambas as escolas não aprovam o fato de a escola ter que chamar um elemento exterior à dinâmica escolar (polícia) para o restabelecimento da ordem, pois isso é função estritamente da escola.

Estabelecendo uma comparação entre estes dados com os que Menin obteve em pesquisas anteriores analisando casos de injustiça que se referiam a diferentes espaços sociais (Menin, 2000b e 2002), vê-se que predominam, tanto naquela pesquisa como em pesquisa realizada em 2003, exemplos derivados da justiça retributiva e legal, o que confirma ainda classificação de Piaget (1932/1977) e Kohlberg (1992) e mostra, segundo esses autores, uma rigidez nos julgamentos dos alunos. Tal rigidez pode ser, no entanto, um indício de que especificamente na escola não haja um diálogo entre professores e alunos em relação ao que se considera justo ou injusto quanto à elaboração e decisão sobre normas e regras de convivência escolar e seja comum que se atribua o estatuto de injustas a penalidades vistas como arbitrárias, tais como "chamadas de atenção" ou "redução de notas".

Em nenhuma das séries ou escolas examinadas, a escola apareceu, nas expressões espontâneas dos alunos, intensamente como uma instituição injusta; embora também esteja longe de se mostrar como a "comunidade justa" de Kohlberg (1997). Exemplos de injustiças são assinalados como freqüentes entre os alunos.

Considerando a escola como cena, essas injustiças têm dois agentes principais: professores e alunos. Por um lado, os professores foram vistos como punindo, muitas vezes com o uso de notas baixas, os alunos por seus comportamentos, ou ainda, acusando-os injustamente; por outro lado, os próprios colegas são apontados como injustos nas relações entre si e desrespeitosos com seus professores. Curiosamente, das duas escolas examinadas, foi na particular que se destacaram os professores como agentes de injustiça retributiva e distributiva. $\mathrm{Ou}$ seja, parece que na escola particular os alunos identificaram a possibilidade de uma autoridade como o professor ser injusta; enquanto na escola pública essa autoridade foi questionada. Questiona-se por um lado que valores morais estariam ancorando a obediência/observância dos alunos de ambas as escolas em relação às normas escolares e, por outro lado, que possibilidades têm os alunos de refletir sobre essas normas e sua incorporação pelos professores.

As diferenças de respostas obtidas entre os alunos parecem ser mais evidentes em relação ao fato de pertencerem a diferentes classes sociais. Alunos de escola pública tendem a relativizar a infração das normas escolares em virtude das necessidades pessoais como os dos dilemas propostos na Tabela 7 , provavelmente pelo fato de estarem mais propensos a vivenciar situações que suscitem estas infrações. Assim, de acordo com os níveis de julgamento moral proposto por Kohlberg (1992), vemos que há mais respostas de nível 1 , centradas nos benefícios próprios e riscos de punição entre os alunos de escola pública que entre os de escola particular, centrados por sua vez em respostas de nível 2 , baseadas em valores e papéis convencionais.

Outro elemento diferenciador, entre escolas particulares e públicas, nas representações de injustiças relaciona-se ao fato de os alunos de $5^{a}$ série de escola pública terem dificuldades em reconhecer o termo "injustiça". Ao que parece, os alunos não têm familiaridade com a terminologia ou ainda não têm meios de discussão sistemática de situações injustas, o que pode dificultar a identificação dessas situações injustas. Ora, representações da realidade se constroem na medida em que haja fatos a explicar, problemas a resolver. Como afirma Moscovici, (1978), as representações sociais tornam familiar o que é estranho. Assim, se situações de injustiça na escola são vistas como familiares, rotineiras, se fazem parte da condição normal da escolarização, não há razão para problematizálas ou dar-lhes a representação de injustiça. Assim, notamos que os alunos, principalmente de escolas públicas, não identificam espontaneamente situações de injustiça não sabendo dar 
exemplos, mas marcaram a sua ocorrência em situações dadas pelas questões ou quando as normas escolares se opõem às necessidades vividas. Nesses casos, as injustiças são "reconhecidas" e talvez, só ai, nomeadas de injustiça.

Segundo Guareschi (1993), as acusações dos alunos sobre as injustiças cometidas pelo professor podem estar associadas às representações que os alunos possuem da escola como instituição, cujas normas e regras foram e são estabelecidas sem sua participação. Há o estabelecimento de uma relação verticalizada segundo a qual o poder e sua manifestação se concentram nas figuras representativas (diretor, vice-diretor, inspetor, professor, etc.) deste ambiente, o que acaba por "naturalizar" e determinar os papéis e suas funções no espaço e na dinâmica escolar. Uma manifestação que ousa desafiar essa passiva obediência tem sido alvo de muito questionamento e preocupação na atualidade do contexto pedagógico-educacional. A indisciplina e suas manifestações têm sido alvo de queixas constantes dos professores que discutem o tema, mas não suas práticas de controle.

Uma proposta da escola como "comunidade justa" que pode ser vista em Kohlberg (1997), e descrita em Biaggio (1997), propõe um modelo de escola e de educação que permita a manifestação do aluno em suas dimensões política, social, afetiva, educacional, enfim, em seu sentido pleno, tendo em vista o desenvolvimento de uma moral baseada no senso de justiça e no respeito ao grupo. Nessa escola situações de conflitos, dificuldades de relacionamento, situações de injustiças são alvos de reflexão, discussão e proposição de revisão das normas.

Nesse sentido acreditamos que trabalhos sobre injustiça na escola poderiam auxiliar o professor, em sua prática pedagógica, a estimular o aluno a participar mais democraticamente da dinâmica escolar de forma a vivenciar diferentes papéis e a não mais se colocar como vítima ou agente de injustiça, mas como co-autor de normas e regras com as quais concordam em obedecer. Esse seria um verdadeiro exercício da autonomia moral.

\section{Referências bibliográficas}

ASSMAR, Eveline M. L. Interação social e reação à injustiça. Revista Psicologia: teoria e pesquisa, Brasília, v. 14, n. 2, p.121126, maio/ago 1998.

A psicologia social e o estudo da justiça em diferentes níveis de análise. Revista Psicologia: reflexão e crítica, Porto Alegre, v.3, n. 3, p. 497-506, 2000.

BIAGGI0, Ângela M. B. Kohlberg e a comunidade justa: promovendo o senso ético e a cidadania na escola. Revista Psicologia: reflexão e crítica, Porto Alegre, v. 10, n. 1, p. 47-69, 1997.

DOISE, W. Sensibilité des jeunes aux droits de l' homme. In: . La perception des droits de l'homme dans la societé contemporaine. Paris: Centre de Education de la vie politique française de l'Institut de droit compare de L'Universite de Paris. (Rapport final, v.1), 1991.

DOISE, W.; HERRERA, M. Déclaration universelle et représentations sociales des droits de l'homme : une étude à Genève. Revue Internacionale de Psychologie Sociale, Grenoble,v.2, p.87-107, 1994b.

DOISE, W. et al. Values and perceived conflicts in the social representations of human rights: feasibility of a cross-national study. Swiss Journal of Psychology, Berna, v. 53, n.4, p.240-251, 1994a.

La représentation sociale des droits de l'homme: Une recherche internationale sur l'énténdue et les limites de l'universalité. Journal International de Psychologie, Paris, v.30, p.181-212, 1995.

GRUPO DE PESQUISA VALORES, EDUCAÇÃO E FORMAÇÃO DE PROFESSORES. Relatório da pesquisa: ética na escola, valores de alunos. FCT-Unesp, 2002. 
GUARESCHI, Neuza M. F. A criança e a representação social de poder e autoridade: negação da infância e afirmação da vida adulta. In: SPINK, M.J. 0 conhecimento no cotidiano: as representações sociais na perspectiva da Psicologia Social. São Paulo: Brasiliense, 1993, p. 212-233.

HUTZ, C. S.; DELL'AGLIO D. Teorias e modelos evolutivos de justiça distributiva: uma revisão da literatura. Psicologia: reflexão e crítica, Porto Alegre, v. 8, n.2, p. 169-180, 1995.

JAKUBOWSKA, I. Droit et Justice chez les enfants et les adolescents. Droit et Société, Vaucresson, v. 19, p.287-295, 1991.

JAKUBOWSKA, I. ; BRANICKA, I. Droit et Justice dans une société post-totalitaire: I'exemple de la Pologne. Revue d' études comparatives Est-Ouest, Paris, v.3, p.15-35, 1994.

JODELET, D. Representações sociais: um domínio em expansão. In: 1993, p.17-44.

As representações sociais. Rio de Janeiro: UFRJ,

KOHLBERG, L. Psicologia del desarrollo moral. Bilbao, Espanha: Biblioteca de Psicologia, 1992.

KOHLBERG, L.; POWER, F.C.; HIGGINS, A. La educacion moral ségun Laurence Kohlberg. Barcelona: Editorial Gedisa, 1997.

MENIN, M.S.S. Autonomia e heteronomia às regras escolares: observações e entrevistas na escola. 1985. Dissertação (Mestrado)- Instituto de Psicologia, Universidade de São Paulo, São Paulo, 1985.

Representações sociais de justiça em adolescentes infratores: discutindo novas possibilidades de pesquisa. Psicologia: reflexão e crítica, Porto Alegre, v. 13, n.1, p.59-72, 2000a.

Representações sociais de lei, crime e injustiça em adolescentes. 2000b. Tese (Livre-Docência)- Faculdade de Ciências e Tecnologia, Universidade do Estado de São Paulo, Presidente Prudente, 2000b.

Representações sociais de injustiça em adolescentes de escolas públicas e particulares. Psicologia da Educação: Revista do Programa de Estudos Pós-Graduados, São Paulo, v. 14-15, p. 239-264, 2002.

MOSCOVICI, S. A representação social da psicanálise. Rio de Janeiro: Zahar Editores, 1978. (Original publicado em 1961)

PERELMAN, Ch. Ética e direito. São Paulo: Martins Fontes, 1999.

PIAGET, J. 0 julgamento moral da criança. São Paulo: Mestre Jou, 1977. (Original publicado em 1932).

SÁ, C. P. de. Representações sociais: o conceito e o estado atual da teoria. In: SPINK, M. J. 0 conhecimento no cotidiano: as representações sociais na perspectiva da Psicologia Social. São Paulo: Editora Brasiliense, 1993.

A construção do objeto de pesquisa em representações Sociais. Rio de Janeiro: Eduerj, 1998.

Recebido em 29.08.03

Aprovado em 19.04.04

Maria Suzana De Stefano Menin é professora da Faculdade de Ciências e Tecnologia da UNESP de Presidente Prudente. Doutora Livre Docente em Psicologia da Educação e do Desenvolvimento e Coordenadora do Programa de Pós-Graduação em Educação desta instituição. E-mail: menin@prudente.unesp.br.

Renata Aparecida Carbone é graduada em Pedagogia pela Universidade Estadual Paulista, UNESP, Campus de Presidente Prudente. Foi aluna bolsista Fapesp, que financiou pesquisa sobre Injustiça na Escola. 